\title{
Podemos confiar nas medidas de confiança?
}

\author{
Susanne Lundåsen
}

Mid Sweden University College e Åbo Akademi University, Finlândia

\section{$\underline{\text { Resumo }}$}

A variável 'confiança' ganhou ultimamente largo uso nas pesquisas em ciências sociais e poucos conceitos parecem ter atraído tanta atenção de uma ampla variedade de disciplinas acadêmicas. Na ciência política. Nas teorias sobre capital social e cultura política, enfatizando sua importância para a democracia, a confiança tem sido considerada uma variável essencial para a compreensão das sociedades.

Este trabalho aborda algumas das diferentes teorias que estão ligadas tanto à definição como aos efeitos da confiança generalizada e depois, tratará de questões ligadas à incerteza das medidas de confiança generalizada.

Palavras-chave: Confiança, capital social, cultura política, medição

\begin{abstract}
The variable trust has become widely used in the social science research lately and few concepts seem to have attracted so much attention from such a broad variety of academic disciplines. In political science in the theories on social capital and political culture, emphasizing its importance for democracy, trus has been seen as na essential variable for the understanding of societies. In social capital theory the generalized interpersonal trust is often given a particularly important role to initiate virtuous circles of development in the societies.

This paper will treat some of the different theories that are connected both to the definition and the effects of generalized trust and then issues connected to the uncertainty of the measurements of generalized trust.
\end{abstract}

Key words: Trust, social capital, political culture, measurement 


\section{Introdução}

A variável "confiança" ganhou ultimamente largo uso nas pesquisas em ciências sociais e poucos conceitos parecem ter atraído tanta atenção de uma ampla variedade de disciplinas acadêmicas. Na ciência política, nas teorias sobre capital social e cultura política, enfatizando sua importância para a democracia, a confiança tem sido considerada uma variável essencial para a compreensão das sociedades. Na teoria do capital social, a confiança interpessoal generalizada ganha um papel muito importante no início dos círculos virtuosos de desenvolvimento das sociedades.

Derivada principalmente da pesquisa psicológica, a confiança interpessoal foi associada inicialmente a traços da personalidade como misantropia, mas muitas teorias trouxeram uma diversificação das definições e dos aspectos da confiança que são estudados. Apesar dessa diversificação das teorias, o modo mais comum de operacionalizar a confiança generalizada é por meio de surveys. Com freqüência, uma única questão sobre confiança é considerada suficiente para avaliar a confiança generalizada.

Este ensaio aborda algumas das diferentes teorias que estão ligadas tanto à definição como aos efeitos da confiança generalizada e depois, tratará de questões ligadas à incerteza das medidas de confiança generalizada. Defendemos a precaução na interpretação dos resultados de surveys.

\section{Confiança e teoria}

Este trabalho é sobretudo teórico e tratará do conceito de confiança generalizada, mas antes de fazê-lo, é preciso apresentar uma visão geral do conceito. É principalmente nas teorias sobre capital social que se observa uma atenção maior sobre os efeitos da confiança generalizada entre os cidadãos. Poucos tópicos de pesquisa têm atraído tanto interesse numa tal variedade de disciplinas do que a confiança (cf. Yamagishi, 1998). O espectro vai da economia à psicologia, passando pela sociologia e a ciência política. É óbvio que isso resultou numa variedade de definições do conceito que precisamos discutir aqui.

Diz-se que a confiança generalizada, ao contrário da confiança dentro do grupo e a desconfiança fora do grupo, exerce importantes influências sobre vários aspectos da sociedade e, em seu estudo sobre a Itália, Putnam (1993) sustentou que diferentes níveis de confiança generalizada e, posteriormente, diferentes níveis de capital social levaram a níveis diversos de desenvolvimento. Encontram-se conclusões semelhantes sobre a importância da confiança para os níveis de desenvolvimento das sociedades em Fukuyama (1995).

O que é então a confiança? Para Rosenberg (1956), a confiança relaciona-se 
com a fé nas pessoas, que está provavelmente ligada ao fato de que alguém manterá sua palavra (Robinson \& Jackson, 2001). Mas no artigo de Deutsch (1958, p.265), a definição de confiança compreende tanto a noção de "relevância motivacional" como a de "previsibilidade". Esse conceito de confiança é um pouco mais sofisticado, na medida em que envolve expectativas de eventos que ocorrerão no futuro e a possibilidade de sofrer algum tipo de perda se a confiança não for correspondida. Em outras palavras, há um elemento de risco envolvido. Sua definição de um indivíduo com confiança em um determinado evento é "se ele espera sua ocorrência e sua expectativa conduz a um comportamento que ele percebe ter conseqüências motivacionais maiores se a expectativa não for confirmada do que conseqüências motivacionais positivas se for confirmada" (Deutsch ,1958, p.266).

Essa definição de confiança contém também a distinção entre confiar e apostar, quando a chance da ocorrência de um certo evento é pouco provável e ainda assim estamos dispostos a correr o risco. Esses comportamentos são definidos como "patologias da confiança" e não devem ser confundidos com a confiança verdadeira. A situação oposta ocorreria quando o risco envolvido é tão baixo que em vez de confiança, seria mais apropriado usar a palavra "certeza" (cf. Levi, 1998). Para Yamagishi (1998), a confiança generalizada é a expectativa básica de um comportamento não-explorador da contraparte, até prova em contrário. Yamagishi também enfatiza a relevância do risco ou da incerteza social ao tratar da confiança e faz a distinção entre confiança e segurança. A segurança ocorre quando há pouca ou nenhuma incerteza quanto ao comportamento da contraparte e portanto, o risco é muito limitado. Yamagishi (1998) usa o exemplo da sociedade japonesa, onde, à primeira vista, algumas ações poderiam ser interpretadas como envolvendo confiança, mas na verdade, as convenções sociais constrangem tanto o comportamento que elas devem ser classificadas como segurança. Gautschi (2000) também enfatiza o elemento de incerteza envolvido na confiança:

"Confiar em alguém" implica a possibilidade de ficar desapontado. Uma vez depositada a confiança, ela pode ser tanto honrada como violada pelo depositário. [...] Uma vez que assumimos que a confiança é uma decisão binária (isto é, a confiança é depositada ou retirada), "ser cauteloso" significa, portanto, que consideramos pequena a perda provável devida à confiança mal depositada [...]. Porém, assumir o risco de confiar pode valer a pena, pois é a única maneira de obter informação sobre os incentivos do depositário. Ademais, depositar e posteriormente honrar a confiança garante um retorno a ambos os atores que é maior do que seus retornos quando se retira a confiança (Gautschi, 2000, p.131).

\footnotetext{
* Em inglês, a autora distingue entre trust (confiança) e confidence, que além de confiança, pode ser fé, segurança. Preferimos "certeza", para enfatizar a distinção (N.T.).
} 
Essa noção de confiança assinala também o que pode influenciar o comportamento de um indivíduo: a probabilidade de ocorrer um evento negativo e a informação eventual sobre a contraparte. Porém, em situações com N participantes, não parece factível obter informações sobre todo mundo. De acordo com Bacharach e Gambetta (2000), há sinais que os indivíduos usam para interpretar a confiabilidade dos outros. Mas outro modo de transferir confiança de um grupo de pessoas conhecidas para um nível generalizado de pessoas é sugerido por Coleman (1990), em que mediadores podem facilitar a transferência. Por exemplo: A conhece $B$, mas não conhece $C$, que é conhecido de $B$; $A$ pode então confiar em $C$ por meio da relação que $A$ tem com $B$. Se $C$ não corresponder à confiança de $A, A$ pode então retaliar B. Porém, nesse contexto racional é difícil ver como se pode confiar nas pessoas "em geral"; pois a confiança está relacionada com a informação e o contexto em cada situação específica.

Fisman e Khanna lembram que há autores que consideram a propensão à confiança uma variável exógena e que a decisão de confiar ou não nem sempre é racional ou está relacionada com a quantidade de informação disponível. No entanto, eles dizem que, mesmo que a confiança no nível individual seja considerada exógena, a proporção de confiantes encontrada numa população, ou seja, no nível agregado, está relacionada com o fluxo de informação, o que daria crédito ao ponto de vista comportamental (Fisman \& Khanna, 2000). Assim, ainda que a confiança não pareça ter bases puramente racionais e informacionais, ela também não se parece com uma variável completamente exógena, fixada de uma vez para sempre. Para Kramer (1999), a abordagem totalmente racional da confiança como um comportamento provavelmente exagera as capacidades cognitivas dos sujeitos no que se refere, por exemplo, ao processamento de informações e cálculos de ganhos. Kramer sugere uma integração dos modelos que tratam a confiança como uma dependente relacional e contextual com os modelos de escolha racional. O modelo racional constituiria um "fundamento aritmético", mas os fatores sociais e situacionais também deveriam ser incluídos (Kramer, 1999).

Hwang e Burgers correlacionam a confiança com dois outros elementos, a saber: cobiça, "a tentação de ganhar o benefício extra obtido pela não-cooperação unilateral, em vez de cooperação mútua", e medo, "a ansiedade de perda pela vitimização, em vez do status quo ou a não-cooperação mútua". Esses dois elementos influenciam a propensão para a confiança. Eles também acrescentam várias propriedades à confiança, entre elas o fato de que a confiança "não é uma condição suficiente da cooperação", embora necessária, e que ela atenua dois tipos diferentes de risco, "o risco de ser vitimado e o risco de perder um parceiro confiável" (Hwang \& Burgers, 1997, p.70). Porém, uma terceira propriedade interessante da confiança é que mesmo que elimine o elemento de medo na relação 
de confiança, ela não é capaz de tirar inteiramente o elemento de cobiça. Isso leva esses autores à conclusão de que mesmo numa situação em que exista confiança plena, isso não garante a cooperação. É uma questão interessante o fato de que a confiança não seja capaz de eliminar sozinha a cobiça; para limitar a probabilidade de um comportamento explorador é preciso algo mais. As instituições que têm uma função de controle talvez sejam capazes de limitar o comportamento de exploração (cf. Levi, 1998; Rothstein, 2000b). Mas não haveria também necessidade da internalização de certos valores a fim de ter um comportamento confiante em contextos onde não há nenhum controle? Um certo controle sobre o comportamento é exercido de dentro, por meio de sentimentos de culpa e altruísmo, por exemplo (cf. Jones, 1998). As instituições respondem pelas condições mínimas para a criação da confiança, mas dificilmente podem induzir a criação de redes intrincadas entre os indivíduos.

Para Putnam (1993), a confiança é uma espécie de bem de valor variável que aumenta se é usado e diminui se é deixado sem uso. De acordo com Luhmann (1979), a confiança é importante porque reduz a complexidade da sociedade e possibilita que a vida social decorra com mais suavidade. Yamagishi (1998) também defende a necessidade da confiança para haver prosperidade e superar os equilíbrios sub-ótimos em diferentes contextos.

O discurso do aumento relativo da confiança com o uso, se for levado um pouco adiante, como faz Putnam (1993), conduz à criação de círculos virtuosos ou viciosos de desenvolvimento na sociedade. Em sociedades nas quais ninguém confia em ninguém, como no sistema de rádio-táxi de Palermo (Sicília) ${ }^{1}$ descrito por Gambetta (1996), qualquer tentativa de criar desenvolvimento se torna extremamente difícil. Quando a expectativa geral é a de que o princípio fundamental da lei, que estabelece que os acordos serão respeitados, será rompido, então é racional não confiar (cf. Hardin, 1997; Rothstein, 2000a; Rothstein, 2000b). O equilíbrio resultante de nunca confiar é muito estável e parece criar uma série de efeitos colaterais negativos, assim como o equilíbrio onde prevalece a confiança parece produzir efeitos positivos, tal como Putnam (1993) sustenta em seu estudo sobre a Itália, onde se pode ver a origem das diferenças entre a eficiência institucional no Norte e no Sul nas diferenças de confiança e capital social. A iteração de um comportamento cooperativo em resposta a um comportamento cooperativo e a retaliação quando não há cooperação, tal como sugerida pela teoria dos jogos na estratégia olho-por-olho, encontra seu equivalente no teorema popular (folk theorem) (cf. Fudenberg \& Tirole, 1991). Whitmeyer (2000) também leva em

\footnotetext{
${ }^{1} \mathrm{O}$ autor descreve como é difícil criar um sistema de rádio-táxi que funcione devido à falta de confiança entre os taxistas. Se um motorista responde ao chamado da central, os outros suspeitam que ele não está tão perto do endereço da chamada quanto declarou e às vezes tentam pegar a corrida dizendo que estão mais próximos do que o primeiro taxista. A situação toda fica muito complicada para administrar e o sistema de rádio-táxi foi suspenso por um tempo (Gambetta, 1996).
} 
consideração o efeito dos sistemas de reputação positiva, tais como as certificações, prêmios, no desenvolvimento da confiança. Mas o tipo de confiança discutida por Whitmeyer relaciona-se mais com a confiança em contextos específicos e entre indivíduos do que com um nível generalizado.

Para os economistas, a confiança implica a propensão a cooperar; onde há confiança antes, há um comportamento cooperativo em um jogo do dilema do prisioneiro (cf. La Porta et al., 1997). Embora Hwang e Burgers e outros sustentem que a confiança não é suficiente para assegurar a cooperação, ela altera significativamente a probabilidade de um comportamento cooperativo. Alguns estudos experimentais mostraram que as pessoas cooperam mesmo em alguns jogos do dilema do prisioneiro simples, com uma certa expectativa de imparcialidade e cooperação (La Porta et al., 1997; Hayashi et al., 1999). De acordo com Hayashi (1999), o comportamento cooperativo em um jogo do dilema do prisioneiro simples está religado ao fato de que muitos participantes tratam o jogo como se fosse um jogo de segurança.

Para Levi (1998), a confiança não tem uma única fonte, mas deriva de uma variedade de fontes. Para Coleman (1990), a família é uma fonte importante de criação de confiança, enquanto que para Putnam (1993), a confiança é criada e reforçada pelas densas redes horizontais ligadas à sociedade civil. A confiança generalizada também pode ser facilitada pela ação do Estado, de acordo com Levi (1998). Este autor refere-se também ao fato de que sem confiança nas instituições e no Estado, o mundo hobbesiano de medo e insegurança estaria bem perto. Para ele, muitos autores que escreveram sobre o assunto negligenciaram a importância do Estado na instauração da confiança generalizada. Mas para Ruthstein (2000b), é necessário que haja confiança nas instituições para ocorrer uma mudança nos níveis de confiança generalizada. Sem esse requisito básico, seria impossível instaurar qualquer confiança generalizada. Mas pode o Estado explicar a complexidade de redes superpostas que existem em áreas com um alto capital social? Temos o exemplo da associação de crédito mútuo na região da Emilia Romana, apontada por Putnam (1993) como uma das regiões da Itália com alto capital social: um membro do conselho de direção explicou que a confiança mútua era seu maior ativo. Cada membro garantia o crédito dado a outro membro, enquanto o capital da associação constituía a garantia. Nesse caso, o mecanismo de transferência de confiança era exatamente o descrito por Coleman (1990), com a mediação de uma pessoa e a extensão para todo o grupo. Uma vez que a cooperativa tinha um grupo grande demais de membros para que todos se conhecessem, os membros tinham de confiar no julgamento da confiabilidade expresso por outro membro quando outra pessoa queria entrar para a cooperativa. ${ }^{2}$

\footnotetext{
${ }^{2}$ Até aquela data, nenhum dos créditos concedidos havia sido perdido (comunicação pessoal, 3 de abril de 2000).
} 
De um ponto de vista mais psicológico, a confiança pode ser dividida em três níveis diferentes: confiança generalizada (na natureza humana), confiança relacional (relacionada com pessoas conhecidas específicas) e confiança na rede (nível intermediário relacionado com as redes sociais ou familiares) (Couch \& Jones, 1997), Para estes autores, pelo menos as confianças relacional e generalizada são duas variáveis separadas; quanto à confiança na rede, não está claro se ela se distingue suficientemente das outras duas variáveis.

Qual é então a diferença entre confiança dentro do grupo e confiança generalizada? No primeiro caso, a confiança está relacionada a pessoas que são conhecidas pessoalmente por quem confia e o risco é bastante limitado devido ao acesso à informação e à história do comportamento anterior. La Porta (1997) afirma que a inclinação a confiar em estranhos tem importância maior devido às implicações envolvidas na intensificação do comportamento cooperativo geral. Com efeito, a confiança generalizada ou social está entre as coisas que diferenciam as sociedades com capital social alto ou baixo, segundo Putnam (1993). A confiança generalizada aumentaria a probabilidade de conseguir uma reciprocidade geral e, portanto, facilitaria a ação coletiva. Pode haver muita confiança dentro do grupo, como na família, mas baixa confiança nos outros em geral, tal como descrito no familismo amoral de Banfield. ${ }^{3}$ O que não tornaria mútuas essas duas condições. Yamagishi (1998) diz que as relações estreitas dentro do grupo têm um efeito de "fechamento" em relação ao grupo de fora, inibindo a criação de confiança generalizada. Para Putnam (1993), há uma diferença entre confiança densa e delgada, em que a densa seria a confiança baseada no conhecimento direto e iterativo (face a face) entre os indivíduos, com baixo risco, ao passo que a delgada seria mais uma confiança mediada, com conhecimento limitado e risco maior envolvido. Essa última forma de confiança é semelhante ao argumento de Granovetter (1973) sobre a força dos laços fracos. Trata-se de uma espécie de confiança em rede em que a confiança pode viajar como nos modelos apresentados por Coleman (1990).

Para Yamagishi (1998, p.10), a cultura fechada e chamada coletivista, em que as pessoas cooperam mais umas com as outras (grupo interno) do que com pessoas de outros grupos (grupo externo), semelhante ao modelo de Tönnies da Gemeinschaft, poderia chegar ao ponto em que um comportamento mais aberto em relação ao exterior seria mais lucrativo. Yamagishi exemplifica com a sociedade japonesa, que teve um forte desenvolvimento econômico, embora seja uma sociedade de baixa confiança, que deporia contra as teorias de Fukuyama e Putnam. Porém, a cultura coletivista parece produzir equilíbrios sub-ótimos no longo prazo (Yamagishi, 1998). A afirmação é que a "sociedade coletivista produz

\footnotetext{
${ }^{3}$ Embora muito contestado por Sabetti (2000), por exemplo.
} 
segurança, mas destrói a confiança" (Yamagishi, 1998, p.10). O mesmo autor sustenta que onde há maior necessidade de confiança, ou seja, nos contextos de incerteza social, há também maior dificuldade de produzi-la.

Inglehart (1999) mostra que há uma forte correlação entre governo democrático e confiança generalizada. Por exemplo, os países da Europa que apresentam os menores índices na escala da confiança estão, em geral, entre aqueles com uma história de interrupção do regime democrático. Porém, trata-se de uma tarefa empírica bastante difícil estabelecer qualquer relação causal entre essas duas variáveis (cf Rothstein, 2000b), pois elas parecem interdependentes. No entanto, sabe-se que muitos regimes autoritários e totalitários tentaram criar um clima de desconfiança, onde ninguém deve confiar em ninguém, entre outros motivos, para reduzir a possibilidade de mobilização das massas. Hardin (1997, p.14) dá o exemplo da sociedade napolitana do século XVIII que foi destruída pelo domínio espanhol: “Os espanhóis criaram uma nova aristocracia, dependente do apoio espanhol e, desse modo, substituíram uma sociedade baseada na confiança por uma baseada em outro conceito igualmente escorregadio: honra". As prisões também são apresentadas como exemplos de ambiente em que a desconfiança entre os prisioneiros é estimulada pelos guardas a fim de facilitar seu controle (Hardin, 1997). Hardin (1999) afirma também que pode não ser totalmente bom ter cidadãos confiantes numa democracia, onde a confiança cega pode até ser indesejável e produzir efeitos colaterais negativos, tais como cidadãos que não questionam as autoridades.

Contudo, é interessante observar que Yamagishi et al. (1999) descobriram que pessoas com altos índices na escala de confiança são também menos fáceis de enganar do que aquelas que apresentam índices baixos na mesma escala. Explicase o aparente paradoxo pelo fato de que os indivíduos com alta inteligência social são capazes de manter altos níveis de confiança, enquanto que as pessoas com capacidade empática mais baixa não possuem essa capacidade. Os indivíduos que revelam índices altos na escala de confiança generalizada são também mais sensíveis à informação negativa relacionada com a confiabilidade de um ator (Yamagishi et al., 1999). Invertendo esse resultado, haveria a possibilidade de pessoas com baixa confiança serem exploradas com mais facilidade se decidirem confiar em alguém, pois são menos rápidas para captar a informação negativa do que aqueles que confiam muito.

\section{Capital social e confiança}

De acordo com alguns autores, o capital social está fortemente ligado à confiança generalizada (cf. Putnam, 1993; 1995), de tal modo que às vezes é difícil distinguir entre o que são os efeitos ou as causas do capital social e o que 
ele realmente é; o capital social gera confiança e normas de reciprocidade que, por sua vez, geram mais capital social. No estudo de Putnam sobre a Itália (1993), a sociedade civil criava e reforçava a confiança generalizada, permitindo a criação de capital social, a forma particular de capital que possibilita e facilita a ação coletiva. Ele também ajuda a superar dilemas sociais como o do prisioneiro (cf. Ostrom, 1998). Para Rothstein (2000a; 2000b), a noção importante que o estudo de Putnam sobre as regiões da Itália trouxe para a ciência política está na descoberta dos resultados que a falta de confiança generalizada entre os cidadãos produz e que a falta de confiança nas instituições tende a produzir. A estratégia dominante, em termos de teoria dos jogos, numa sociedade que carece de confiança é então não confiar. Como observa Tarrow (1996), o estudo das regiões italianas não pretendia ser um estudo da cultura política, pois incluía apenas variáveis comportamentais e não atitudinais, embora muitos dos estudos seguintes o tenham interpretado em termos de cultura política.

Porém, houve opiniões divergentes sobre os efeitos da participação em associações sobre a confiança generalizada (cf. Stolle, 1998). Para Hooghe (2000), o aumento da confiança generalizada só está presente quando as associações têm um grande número de membros altamente instruídos e talvez se deva aos efeitos de socialização. Permanece sem explicação o modo como a confiança da participação em associações se dissemina para a sociedade circundante. Coleman (1990) vê a possibilidade de transferência de confiança para alguém por meio da mediação, como explicamos acima. O importante é que a criação de normas de reciprocidade e confiança dentro da sociedade civil não fica limitada às associações, mas gera externalidades positivas para a sociedade circundante. A existência de redes horizontais, em que todos os atores são tratados de modo mais ou menos igual, é importante para a criação de normas de reciprocidade, ao contrário das redes hierárquicas, que são negativas e amiúde baseadas em relações de clientelismo (cf. Putnam, 1993).

A importância da confiança na determinação do capital social é contestada por alguns estudiosos que consideram apenas as redes horizontais (por ex., Lin, 2000). Porém, as palavras-chave parecem ser redes horizontais, confiança generalizada e normas de reciprocidade.

\section{Variáveis que influenciam o nível de confiança generalizada}

As medições do nível individual de confiança generalizada encontraram diferentes fatores que influenciam a inclinação para a confiança. Do ponto de vista psicológico, acredita-se que variáveis concernentes aos primeiros anos de vida influenciam os níveis de confiança. Pesquisas empíricas mostraram que a situação de minoria, o status socioeconômico, a idade e a educação têm um impacto sobre a 
confiança (cf. Glaeser et al., 1998; Smith, 1997; Robinson \& Jackson, 2001). As pesquisas indicam que o nível de confiança generalizada aumenta com a idade (Robinson \& Jackson, 2001), enquanto que fazer parte de uma minoria afeta a confiança de forma negativa. Outras variáveis ligadas a experiências passadas do indivíduo, tais como o divórcio, parecem ter um impacto mais incerto (Couch e Jones, 1997; Glaeser et al., 1998; Robinson \& Jackson, 2001). Putnam (1993) leva em conta a importância da sociedade civil e a participação em associações. Os resultados empíricos divergem um pouco sobre o eventual benefício dessa participação (cf. Stolle, 1998). Porém, Glaeser et al. (1998:6) apontam para diferentes fatores que influenciam o comportamento confiante, entre os quais: 1) crenças sobre a confiabilidade dos outros; 2) a capacidade de provocar comportamento confiável dos outros. Às vezes, o segundo fator parece ser esquecido.

Suponha-se que há dois indivíduos $A$ e $B$ que não se conhecem pessoalmente, e que $A$ não é capaz de parecer confiável aos olhos de $B$; então parece racional que $B$ não confie nem coopere com $A$, se $B$ não quiser se tornar um "trouxa" na linguagem da teoria dos jogos. A poderia estar inclinado a cooperar e ser confiável, mas não é digno de crédito de B; então A ficaria numa situação pior se cooperasse, caso estivesse diante de um situação tipo "dilema do prisioneiro". Bacharach e Gambetta (2000) discutem os sinais que são dados conscientemente ou inconscientemente e que depois são usados para avaliar a confiabilidade de uma contraparte. Pertencer a um grupo minoritário parece afetar o nível de confiança generalizada de forma negativa, o que pode estar relacionado com a suspeita do grupo majoritário com respeito ao grupo minoritário (cf. Smith, 1997). No entanto, Yamagishi (1998) abstém-se da idéia de reduzir o estudo da confiança à capacidade de emanar confiabilidade aos olhos da contraparte.

Em nível agregado, a confiança parece estar ligada ao bem estar material a à democracia estável (cf. Inglehart, 1999). Com os números que Inglehart (1997, p.174) apresenta sobre a relação entre confiança generalizada e democracia estável, o r de Pearson é .72 e é significativo no nível .0000 . Olhando de mais perto os países que estão no topo da escala de confiança, vemos que são pequenos, homogêneos e ricos. ${ }^{4}$ No entanto, é tarefa complicada descobrir se o fluxo causal vai da democracia estável para a confiança generalizada ou vice-versa. Inglehart dá o exemplo da Rússia, onde o desenvolvimento democrático não levou a níveis maiores de confiança generalizada. A explicação dada neste caso é que a situação econômica regrediu após a democratização, o que produziu condições de vida piores para a população em geral. Desse modo, parece difícil um aumento de confiança quando não ocorre também um aumento de riqueza (cf. Inglehart 1999).

\footnotetext{
${ }^{4}$ Os países escandinavos, Finlândia e Holanda.
} 
La Porta et al. (1997) examinam a importância da religião para os níveis de confiança generalizada; religiões consideradas hierárquicas, como a católica, a católica ortodoxa e a islâmica, têm um efeito negativo sobre o nível agregado de confiança generalizada. Isso está de acordo com as considerações de Putnam (1993) sobre a Itália, onde o papel da igreja católica se mostrou mais proeminente no sul do país, onde o nível de confiança interpessoal era mais baixo. La Porta et al. (1997) também descobriram empiricamente uma forte correlação entre a proporção de protestantes que viviam em um país e o nível agregado de confiança generalizada. Com efeito, os países classificados por Inglehart (1997) com os maiores índices de confiança generalizada possuem todos uma grande proporção da população que é ou foi protestante. Porém, nem todos os estudiosos concordam em atribuir à religião o papel de variável explicativa (cf. Yamagishi, 1998). A religião pode ser apenas uma variável proxy, e neste caso poderia ser a capacidade de ler e escrever. A educação é uma das variáveis que parece ter um grande impacto sobre a confiança generalizada e o protestantismo, além de não ser considerado uma religião hierárquica, exerceu a imposição (histórica) de conhecer a Bíblia, o que também elevou o nível geral de alfabetização.

\section{Questões de mensuração}

Tem-se dado muita atenção a questões de escala e mensuração em outras disciplinas, tais como a psicologia social, ao passo que as ciências sociais não demonstram o mesmo interesse por esses tópicos, dando preferência aos aspectos teóricos da confiança. Portanto, parece-nos útil examinar a literatura dessa disciplina, pois os métodos por ela desenvolvidos foram usados nas pesquisas de ciência política.

Como já mencionamos, está empiricamente confirmado que há pelo menos duas escalas diferentes de confiança: "confiança no parceiro" (em uma pessoa específica) e "confiança generalizada" (nas pessoas em geral, na natureza humana) (Couch \& Jones, 1997). O que poderia corresponder à confiança densa e à confiança delgada. Mas quando se estuda mais de perto a definição de confiança generalizada aplicada na psicologia social, ela é considerada amiúde uma medida de filantropia/misantropia (cf. Rosenberg, 1956; Couch \& Jones, 1997; Robinson \& Jackson, 2001). Conforme a Enciclopédia Britânica, a palavra filantropia, em sua origem grega, significa "amizade ao homem", e é descrita como "boa vontade para com os homens, especialmente, esforço ativo para promover o bem estar humano". Ao contrário, misantropia é definida com "ódio ou desconfiança da humanidade". As mensurações utilizadas por Couch e Jones (1997, p.333) para detectar a confiança generalizada estavam relacionadas com as expectativas generalizadas com respeito aos outros em situações não estruturadas, como uma medida de "traço amplo e 
global". Isso significa que as medidas de confiança global estão mais ligadas às emoções e a características pessoais do que às experiências de relações passadas (Couch \& Jones, 1997). São estas equivalentes à confiança e desconfiança tal como aplicadas nas ciências sociais? Se não o são, pode haver um problema de especificação. Parece haver uma leve diferença entre o cálculo racional de custo e benefício da cooperação e o tratamento quase exógeno da variável confiança generalizada, como ocorre em parte da literatura psicológica. Apesar dessas diferenças teóricas, as escalas usadas em surveys vêm freqüentemente das ciências do comportamento. Por exemplo, a escala de confiança generalizada usada amiúde em pesquisas das ciências sociais vem da escala de cinco itens de fé nas pessoas de Rosenberg (1956). Porém, é muitas vezes reduzida a uma escala com menos itens.

É interessante observar que embora alguns cientistas sociais não tenham se referido à confiança como uma variável exógena, mas principalmente como comportamental, eles decidiram usar as mesmas medidas da psicologia (cf. Tarrow, 1996).

Um exame mais detalhado da escala de cinco itens de fé nas pessoas e, mais especificamente, das questões utilizadas com freqüência nos surveys revela alguns problemas. A formulação da primeira questão é um tanto ambígua: "Falando em geral, você diria que se pode confiar na maioria das pessoas, ou que é preciso muita cautela ao tratar com as pessoas?" As alternativas de resposta são: (1) É preciso muita cautela; (2) Outra, depende (os respondentes apresentam a alternativa); (3) Pode-se confiar na maioria das pessoas. A ambigüidade da escala está no fato de que os opostos apresentados são questionáveis enquanto opostos (cf. Yamagishi, Kikuchi \& Kosugi, 1999). Cautela e confiança podem não ser os melhores extremos; com efeito, a pesquisa psicológica mostra que elas podem nem pertencer ao mesmo fator. Yamagishi et al. (1999) também afirmam que há uma falácia lógica na formulação da questão, pois abre a possibilidade de que possa haver algumas pessoas não confiáveis, uma vez que menciona a "maioria das pessoas" e não "todas as pessoas". Portanto, não é contraditório confiar nas pessoas em geral e tomar cuidado com aqueles que não são confiáveis.

$\mathrm{Na}$ verdade, os resultados empíricos de estudos comparativos mostram que os respondentes que revelam confiança generalizada baixa também concordam, em larga medida, que é necessário prudência, mas isso não funciona no sentido oposto: os que demonstram alta confiança também mostram altos índices de cautela, sugerindo que essas duas variáveis não são opostas (Yamagishi et al., 1999). A formulação dessa escala torna mais difícil a interpretação subseqüente. Por exemplo, se ocorre uma queda no número de entrevistados que respondem que se pode confiar na maioria das pessoas, parece difícil dizer se a queda é da confiança ou se as pessoas simplesmente se tornaram mais cautelosas, como Yamagishi et al. 
também afirmam. Para esses autores, estamos diante de um tratamento misturado de confiança geral e prudência. Eles também dizem que a outra questão usada no American General Social Survey (GSS), se as pessoas estão "em geral tentando ser prestativas, ou estão cuidando delas mesmas", revela uma medida melhor e menos ambígua de confiança, na medida em que capta as expectativas com respeito ao comportamento dos outros. Essa questão não teve a mesma queda no tempo nos respondentes que disseram que as pessoas tentam ser prestativas do que a observada na questão sobre confiança (Yamagishi et al., 1999).

Smith (1997) examina os estudos que comparam as diferentes formulações da questão da confiança e conclui que ela é muito sensível às palavras utilizadas. Em 1983, fez-se uma experiência que testava as duas formulações diferentes da questão: "Você acha que se pode confiar na maioria das pessoas?" e "Falando em geral, você diria que se pode confiar na maioria das pessoas ou que é preciso ter muita cautela ao tratar com as pessoas?" A primeira formulação da questão gerou $57 \%$ de respostas positivas, enquanto que na segunda formulação, $36,5 \%$ dos entrevistados responderam que "se pode confiar na maioria das pessoas" (Smith, 1997). Outro estudo não-experimental realizado sugeriu outra formulação similar, mas gerou um número mais alto de respondentes declarando confiança (Tabela 1).

A Tabela 1 ilustra as diferenças na formulação e na distribuição das perguntas; embora os números de 1978 não sejam de um estudo experimental, eles indicam uma diferença de vários pontos percentuais na distribuição das respostas. Smith (1997) também apresenta dados que mostram que a questão específica sobre confiança é influenciada pelo contexto. Dependendo das perguntas feitas antes da questão sobre confiança, a parte dos respondentes que escolhem a alternativa da confiança varia. Se são feitas perguntas sobre crime e legalização de drogas antes da questão sobre confiança, a escolha pela alternativa da confiança diminui. Essas diferenças pedem cautela na comparação dos resultados de surveys diferentes, com diferentes formulações, e também na comparação de surveys com a mesma formulação ao longo do tempo, devido aos efeitos do contexto (cf. Smith, 1997). 


\section{TABELA 1}

Diferentes formulações da questão sobre a confiança em estudos americanos

\begin{tabular}{|c|c|c|c|}
\hline Formulação & \multicolumn{3}{|c|}{ Distribuição das respostas } \\
\hline $\begin{array}{l}\text { Você acha que se pode confiar } \\
\text { nas pessoas? } \\
(1983, N=790)(\text { GSS })\end{array}$ & $\begin{array}{l}\operatorname{Sim} \\
57 \%\end{array}$ & $\begin{array}{l}\text { Não } \\
40 \%\end{array}$ & Não sabe $3 \%$ \\
\hline $\begin{array}{l}\text { Falando em geral, você diria } \\
\text { que se pode confiar na maioria } \\
\text { das pessoas, ou que é preciso } \\
\text { ter muito cautela ao tratar com } \\
\text { os outros? } \\
(1983, N=801) \text { (GSS) }\end{array}$ & $\begin{array}{l}\text { Pode-se confiar } \\
\text { na maioria das } \\
\text { pessoas } 36,5 \%\end{array}$ & $\begin{array}{l}\text { É preciso ter } \\
\text { muito cuidado } \\
59,2 \%\end{array}$ & $\begin{array}{c}\text { Não sabe/Outra } \\
4,3 \%\end{array}$ \\
\hline $\begin{array}{l}\text { Algumas pessoas dizem que se } \\
\text { pode confiar na maioria das } \\
\text { pessoas. Outras dizem que é } \\
\text { preciso ter muita cautela ao } \\
\text { tratar com as pessoas. O que } \\
\text { você acha disso? (1978, } \\
\mathrm{N}=1635 \text { (National Opinion } \\
\text { Research Center) }\end{array}$ & $\begin{array}{c}\text { Pode-se confiar } \\
\text { na maioria das } \\
\text { pessoas } 48 \%\end{array}$ & $\begin{array}{l}\text { É preciso ter } \\
\text { muito cuidado } \\
51 \%\end{array}$ & $\begin{array}{c}\text { Não sabe/Outra } \\
1 \%\end{array}$ \\
\hline $\begin{array}{l}\text { Falando em geral, você diria } \\
\text { que se pode confiar na maioria } \\
\text { das pessoas ou que é preciso } \\
\text { muita cautela ao tratar com os } \\
\text { outros? }(1978, N=1528) \text { (GSS) }\end{array}$ & $\begin{array}{c}\text { Pode-se confiar } \\
\text { na maioria das } \\
39,9 \%\end{array}$ & $\begin{array}{l}\text { É preciso ter } \\
\text { muito cuidado } \\
55,7 \%\end{array}$ & $\begin{array}{c}\text { Não sabe/Outra } \\
4,4 \%\end{array}$ \\
\hline
\end{tabular}

Fonte: Smith, 1997

Porém Smith (1997) conclui que o índice composto de misantropia dos três itens diferentes do GSS (incluindo confiança, prestimosidade e eqüidade) é relativamente equilibrado e estável ao longo do tempo. O mesmo autor também descobriu que a porção de entrevistados que escolhe a resposta "Não sei" ou outra varia conforme se trate de uma pesquisa auto-administrada em que essa alternativa é apresentada explicitamente, ou se é uma pesquisa administrada pelo entrevistador em que a alternativa não é lida e tem de ser apresentada espontaneamente pelo respondente. Isso talvez não seja um efeito muito estranho e pode ser válido em um nível mais geral de surveys (cf. Belson, 1981; Krosnick, 1999). Quando a opção "não sei" ou "não tenho opinião" é apresentada explicitamente, ela é selecionada por um grupo maior de respondentes, ocorrendo o contrário se ela não é apresentada (Krosnick, 1999).

Quando se trata de responder a questões de surveys, há sempre um processo cognitivo envolvido no entrevistado enquanto ele responde a pergunta e uma questão definida de modo tão amplo quanto a da confiança pode causar problemas (cf. Smith, 1997; Yamagishi, 1998). O processo de resposta envolve 
vários estágios cognitivos prévios, tais como compreensão, lembrança e julgamento (cf. Belson, 1981). Com a questão específica da confiança, a heurística da lembrança pode ser difícil para o respondente, pois não há pontos de referência no tempo e ela implica um julgamento de toda uma experiência de vida que o tornaria mais sensível ao contexto, de acordo com Smith (1997). Belson (1981) também argumenta que questões complicadas que têm somente duas alternativas (tais como "confia" e "não confia"/ "precisa ter cautela") receberão provavelmente respostas menos pensadas pelos entrevistados. É também menos provável que os respondentes dêem a atenção analítica, desejada pelo pesquisador, à questão formulada da forma citada e, portanto, podem interpretá-la de maneira diferente da desejada (cf. Belson, 1981). A questão também parece dicotomizar a variável confiança: ou se confia, ou não se confia totalmente. Isso não possibilita graus diferentes de confiança, em que ela seja depositada somente até certo ponto.

Com respeito ao problema de interpretação da resposta à questão padrão sobre confiança, Robinson e Jackson (2001) afirmam que uma queda no número de respondentes que escolhem a alternativa de que "se pode confiar na maioria das pessoas" talvez se deva ao fato de que o quadro de referência mudou (cf. Glaeser et al., 1999). Quando a pergunta foi feita em momento anterior, a expressão "a maioria das pessoas" pode ter provocado associações com vizinhos e amigos, enquanto o outro generalizado de hoje é o estranho potencialmente perigoso que anda nas ruas. Pode haver outro questionamento da validade interna, se o quadro de referência para responder à pergunta for amigos e pessoas conhecidas do entrevistado, em especial na pesquisa cujo foco é o capital social. A teoria baseia-se na capacidade de confiar em um estranho e parece haver uma boa diferença se a pessoa responde à questão pensando em indivíduos que conhece ou se pensa em um estranho. A ambigüidade da questão poderia levar o respondente a escolher uma das possíveis interpretações, gente conhecida ou estranhos, sem que o pesquisador saiba qual das interpretações foi escolhida (cf. Belson, 1981). Nesse caso, o pesquisador está provavelmente interessado em "confiança delgada", mas pode estar medindo "confiança densa" (cf. Putnam, 1993). A questão é: em que medida esse fator pode influir no resultado? Sem um exame empírico mais aprofundado dessa questão, é difícil fazer estimativas do viés eventual, seja ele distribuído aleatoriamente ou sistêmico. É possível também que haja diferenças entre países na interpretação de "a maioria das pessoas" que podem levar os entrevistados a responder, na verdade, a questões diferentes em diferentes países, no pior cenário. Em sociedades em que há uma grande diferença entre confiança densa e delgada, ou confiança no grupo interno e externo, parece importante compreender a definição que os respondentes tem de "a maioria das pessoas". Para dar um exemplo, pode ter importância teórica se os habitantes de um tipo de sociedade Gemeinschaft pensam na "maioria das pessoas" como as pessoas que 
conhecem e, portanto, não corresponderiam às alegações teóricas de incerteza e risco e talvez a tratassem como se fosse uma questão de segurança nos termos de Yamagishi (1998). Alguns resultados empíricos preliminares parecem sugerir que há um viés sistêmico, funcionando no sentido sugerido por Yamagishi (1998) (Miller e Mitamura, a sair).

Devido aos efeitos do contexto e da formulação, é muito arriscado comparar dados ao longo do tempo e entre diferentes formulações, pelo menos se o objetivo for analisar tendências da confiança generalizada baseado somente na única questão sobre confiança (Smith, 1997). Para este autor, é preferível usar um índice baseado numa bateria de questões relacionadas com a confiança para reduzir o viés, em vez de uma única pergunta. Porém, Uslaner (1999, p.126) sustenta que a questão do GSS sobre confiança é boa e mede a "confiança em estranhos", tal como se supõe que uma medida de confiança generalizada deve fazer. Os resultados da análise sobre o declínio ou não da confiança generalizada entre os cidadãos americanos têm sido divergentes (por ex., Putnam, 1995; Putnam, 2000; Robinson \& Jackson, 2001; Yamagishi, 1998; Smith, 1997; Paxton, 1999). É preciso distinguir empiricamente entre efeitos de coorte e variações na variável confiança (cf. Robinson \& Jackson, 2001; Smith, 1997). Yamagishi et al. (1999) também julgam difícil decidir se o que parece ser um declínio na proporção de entrevistados que confiam na maioria das pessoas deve ser atribuído a um declínio da confiança generalizada, ou se trata simplesmente do reflexo de um aumento de cautela dos respondentes.

Um método que parece estar mais próximo das teorias sobre confiança é aquele adotado nos cenários experimentais (cf. Yamagishi, 1998). Os objetivos de surveys e métodos experimentais podem ser diferentes, pois estes costumam ter por alvo principal testar teorias, ao passo que aqueles buscam generalizações. As teorias citadas acima sobre a relação entre confiança e outras variáveis relacionadas com o capital social tratam-na em geral como uma variável comportamental, em vez de atitudinal, no sentido de que são feitas referências à teoria dos jogos, com jogos repetidos, para explicar equilíbrios diferentes em sociedades diferentes (cf. Putnam, 1993). Porém, muitas das medidas nesse campo passaram a tratá-la como variável atitudinal, ou mesmo perto de exógena. 0 desenho experimental da pesquisa parece reduzir a distância eventual entre teoria e variáveis medidas, tendo em vista que se concentra no comportamento, em vez de em atitudes. O outro hiato que parece ser reduzido é aquele entre o comportamento declarado e o real. Yamagishi (1998) concluiu que um jogo do dilema do prisioneiro padrão pode não ser suficiente para avaliar as medidas de confiança, mas sim o que é chamado de jogo do ditador.

Glaeser et al. (2000) combinam as questões padrões de survey e um cenário experimental em que se testa o comportamento confiante dos participantes. É bem 
interessante observar que o survey se sai melhor na previsão da confiabilidade dos participantes do que na de seu comportamento confiante. As questões do GSS sobre confiança parecem ser capazes de dizer se é possível confiar nos participantes em um jogo de confiança, mas não se eles realmente confiam nos outros. A experiência realizada por Glaeser et al. revelou poucas provas da importância da confiança em nível individual para a criação de capital social. Somente duas questões do survey feitas antes do experimento real foram capazes, em certa medida, de prever o comportamento no jogo da confiança; ambas eram sobre estranhos e não pertenciam ao GSS. Para os autores, a confiança ainda pode ser uma variável importante para o capital social em um nível agregado (Glaeser et al., 1999). Porém, o cenário experimental permitiu que pessoas que se conheciam entrassem juntas na experiência e os participantes do experimento interagiam abertamente em pares (não eram anônimos uns para os outros), o que permitiu interações pós-experimentais, inclusive sanções. Portanto, a confiança generalizada não foi realmente testada na situação experimental, mas somente no survey.

Isso parece contradizer algumas das conclusões de Yamagishi et al. (2000), nas quais uma escala de confiança interpessoal parece prever razoavelmente bem o comportamento em um jogo de confiança. A escala de seis itens de confiança elaborada por Yamagishi e Yamagishi (1994) é diferente dos itens do GSS e inclui as variáveis confiabilidade dos outros, confiança generalizada, bondade dos outros, comportamento (recíproco) esperado dos outros e honestidade dos outros.

A diferença entre comportamento declarado e real é um problema clássico dos surveys (cf. Glaeser et al., 2000; LaPierre, 1934). Para alguns pesquisadores, esse tipo de questão ampla reflete a sociedade em torno do respondente, em vez de sua opinião. No nível cognitivo, algumas pesquisas psicológicas afirmam que os respondentes podem nem ter consciência de certas inclinações e comportamentos, ou podem não querer declará-los porque são socialmente indesejáveis (cf. Belson, 1981). Realizaram-se alguns testes, os assim chamados testes de associação implícita, para detectar e medir esse tipo de variáveis amplas, onde se pode incluir a confiança generalizada, que se supõem refletir o comportamento, em vez das atitudes declaradas (cf. Banaji e Hardin, 1996, por exemplo). Seria interessante aplicar esses testes até mesmo a uma variável como a confiança interpessoal.

Hayashi et al. (1999) descobriram que há diferenças em como os indivíduos agem em situações do tipo do dilema do prisioneiro que podem advir dos níveis diferentes de altruísmo ou da natureza cooperativa dos indivíduos. Mas eles também descobriram diferenças em nível agregado, em que alguns participantes pareciam interpretar o dilema como se fosse um jogo de segurança e tendiam a cooperar mesmo quando a cooperação não era lógica (Hayashi et al., 1997). O estudo incluiu uma comparação entre culturas que expôs diferentes motivações por trás do comportamento cooperativo em um dilema do prisioneiro. Para o grupo 
japonês, a interpretação do dilema como um jogo de segurança deveu-se a um sentimento de controle do comportamento da contraparte (Hayashi et al., 1997). Embora os autores interpretem a cooperação dos participantes americanos como causada por um nível mais alto de confiança generalizada nos outros e, portanto, uma inclinação maior a cooperar, esses resultados podem indicar que até mesmo os estudos experimentais devem ter cautela ao interpretar culturas diferentes.

Porém, Yamagishi (1998) sustenta que o dilema do prisioneiro pode não se adaptar para medir a confiança em um estudo experimental. Os participantes que jogam de acordo com uma estratégia de olho por olho em um dilema do prisioneiro repetido não confiam necessariamente na contraparte quando ocorre a cooperação, mas simplesmente agem de acordo com o último movimento da contraparte. Nem mesmo os dilemas do prisioneiro de um único lance estão livres de armadilhas, segundo Yamagishi (1998), porque a cooperação, que não é racional, poderia depender do altruísmo ou de normas sociais que obriguem a cooperar nesses tipos de situações, o que não estaria ligado à confiança. Devido à dificuldades de separar as outras motivações do ato efetivo de confiança, inventou-se o jogo do ditador benevolente (Yamagishi, 1998).

Um exemplo de jogo da confiança é proposto por Berg et al. (1995). A experiência consiste na escolha entre dois conjuntos diferentes de retorno (payoff), um com um retorno "seguro" e o outro com um retorno maior, mas incerto. Para ter acesso ao retorno maior, os participantes terão de confiar que a contraparte, deles desconhecida, irá cooperar e devolver a confiança depositada. Os retornos no jogo não estão estabelecidos, ou seja, diz-se aos primeiros a jogar que podem escolher qualquer (ou nenhuma) quantia de suas dez moedas experimentais para passar ao outro grupo desconhecido (com o qual não podem se comunicar) onde a quantia triplica. Os segundos a jogar podem então escolher quanto (ou nada) querem mandar de volta aos primeiros.

O equilíbrio de $\mathrm{Nash}^{5}$ desse jogo não é confiar no outro, mas os ganhos potenciais são postos de tal forma que a opção de confiar tem um retorno potencialmente maior se o outro decide devolver a confiança. No entanto, Berg et al. (1995) descobriram que alguns escolheram confiar e devolver a confiança de qualquer forma e sugerem que as normas sociais governam o comportamento dos participantes.

Os estudos experimentais comparativos de Yamagishi e seus associados não encontraram diferenças em níveis de confiabilidade entre estudantes japoneses e americanos. A confiabilidade, no jogo do ditador benevolente, a capacidade de redistribuir a quantia de dinheiro passada adiante de um modo eqüitativo, é

\footnotetext{
5 "Em um equilíbrio de Nash, nenhum jogador tem incentivo para mudar sua estratégia unilateralmente. [...] A pura competição desses jogos estimula os jogadores a adotar estratégias tais que ninguém pode explorar o outro." (Sanders, 1994, p.73).
} 
considerada um traço de personalidade e distribuída aleatoriamente, ao passo que - ato de confiar depende das diferenças de confiança generalizada entre as sociedades. Na experiência de Yamagishi (1998), os participantes foram divididos em subgrupos menores em que eles tinham a possibilidade de discutir como agir em um dilema, a fim de obter algum conhecimento sobre seus colegas de experiência. As escolhas feitas nos experimentos eram completamente anônimas, para que os participantes não soubessem quem eram seus pares no grupo para recompensa. Os subgrupos talvez tenham aumentado levemente o nível de cooperação, mas mesmo nesse caso, há a possibilidade de que outras variáveis que não a confiança tenham intervindo na decisão, tais como altruísmo e aversão ao risco, por exemplo, mas há a possibilidade de controlar essas variáveis.

Se uma medida é relativamente robusta, ela deve ser capaz de prever também o comportamento, se essa é a intenção da questão. Mesmo que a confiança seja vista como uma variável ligada à personalidade do indivíduo, ela apresenta um pouco menos de interesse para os cientistas sociais se não tiver nenhum reflexo sobre o comportamento dos indivíduos. Para Yamagishi (1998), que realizou muitas pesquisas nesse campo usando métodos tanto experimentais quanto surveys, os dois se completam, pois sozinhos não são totalmente satisfatórios.

\section{Discussão conclusiva}

A confiança é uma variável usada de modo tão amplo que também ganhou uma grande variedade de definições. Seus componentes fundamentais seriam risco, informação, expectativas em relação ao comportamento da contraparte, a possibilidade de obter confiança dos outros e a possibilidade de ter um retorno maior se confiar. A confiança nem sempre é totalmente racional, mas do ponto de vista analítico, a definição de Levi (1998) parece apropriada ao dizer que a confiança é "racional e relacional", relacional enquanto depende de em quem se deve confiar. Porém, quando se trata de surveys, quando não se fornece nenhuma definição, são as definições de confiança dos respondentes que são usadas para responder à questão. A ciência política, em muitos casos, parece basear-se em mensurações e escalas que derivam de outras disciplinas e com definições às vezes diferentes (cf. por ex. Rosenberg, 1958; Putnam, 1995; Couch \& Jones, 1997). O tratamento da confiança como parte de um traço de personalidade (misantropia/filantropia) gerou as questões amplamente difundidas sobre confiança entre os cientistas sociais que, em geral, parecem encontrar sua relevância teórica como variáveis comportamentais. A personalidade enquanto tal não interessa, mas sim os efeitos sobre o comportamento: confiar ou não confiar. O ponto de vista comportamental continua provavelmente sendo o mais influente na ciência política (cf. Kramer, 1999). 
Há várias armadilhas na questão da confiança, tanto teóricas quanto práticas. É importante lembrar os efeitos de formulação e contexto que existem (Smith, 1997). Esses dois fatores tornam difíceis as comparações entre culturas e ao longo do tempo. No World Value Survey (Inglehart, 1997), Japão e China obtêm resultados relativamente altos na questão sobre confiança do GSS, embora Yamagishi e seus associados (Yamagishi et al., 1999, por exemplo) tenham afirmado em várias ocasiões que o Japão é uma sociedade de confiança baixa e que é necessário distinguir entre confiança e segurança. Sob essa luz, o alto escore do Japão talvez se deva ao fato de os japoneses interpretarem a questão da confiança como se fosse de segurança (cf. Miller e Mitamura, a sair). A incerteza que está por trás desses resultados torna duvidoso usar a questão sobre confiança do GSS isoladamente. Outros cientistas políticos não vêem qualquer problema com a questão (por ex., Uslaner, 1999). Mas embora muita pesquisa de ciência política sobre confiança tenha usado a pesquisa psicológica como ponto de partida, nem sempre se deu a devida atenção à quantidade de pesquisas feitas pelas ciências comportamentais sobre mensurações e a composição de índices de confiança generalizada (por ex., Couch \& Jones, 1997).

O método experimental parece oferecer uma alternativa teórica mais rigorosa. A possibilidade de falsificação da teoria é testada dessa forma, e mesmo que uma teoria inteira não possa ser falsificada, podem-se encontrar importantes armadilhas e incompletudes. Como diz Yamagishi (1998), o método experimental pesquisa as generalizações da teoria, enquanto que a metodologia de survey pesquisa a generalização dos resultados empíricos. Jogos de confiança, tais como o do ditador benevolente, observam a propensão a depositar confiança em um desconhecido.

Porém, parece ser possível afirmar níveis de confiança generalizada e observar diferenças de nível individual e agregado (cf. Yamagishi, 1998). Mas é preciso uma certa cautela para interpretar resultados baseados apenas numa única questão em um survey sobre confiança generalizada. Smith (1997) mostra como os resultados da questão de survey sobre confiança variam em vários pontos percentuais conforme a formulação da pergunta e como dependem das perguntas anteriores às questões sobre confiança. A pergunta "Falando em geral, você diria que a se pode confiar na maioria das pessoas ou que é preciso ter muita cautela ao tratar com as pessoas?" também é tão ampla que poderia ser problemática do ponto de vista cognitivo, pois o entrevistado tem de lembrar de toda uma vida de experiências para dar uma resposta e, portanto, é mais difícil de avaliar. Os estudiosos observaram também a falácia lógica da formulação da questão: em vez de ter confiança num extremo e não-confiança no outro, temos cautela, que não pertence ao mesmo fator de confiança (Robinson \& Jackson, 2001; Yamagishi, 1998). 
No que tange às teorias sobre capital social, a confiança generalizada importante é aquela relacionada com os outros desconhecidos e, portanto, pode haver um problema de especificação quando os entrevistados respondem a questão sobre confiança generalizada pensando em pessoas que conhecem e assim, respondem a uma questão sobre segurança, tal como diz Yamagishi (1998). Isso seria problemático se a confiança declarada dos respondentes apresentasse um viés, chamando de "maioria das pessoas" aquelas que conhecem de maneira sistêmica. As investigações empíricas preliminares sugerem que pode haver um viés sistêmico no modo como "maioria das pessoas" é interpretado (Miller e Mitamura, a sair). Glaeser et al. (1999) concluíram que a questão de survey sobre confiança citada acima parece ter melhor desempenho na previsão da confiabilidade dos respondentes do que na sua inclinação para confiar nos outros. Outra fraqueza advém da incerteza de se a questão mede a confiabilidade dos outros, como uma projeção da confiabilidade do entrevistado, ou se mede realmente a propensão a confiar nos outros. Para Miller e Mitamura (a sair), os vieses sistêmicos encontrados por eles nos testes empíricos da questão padrão sobre confiança do GSS são suficientes para questionar potencialmente os resultados das pesquisas anteriores sobre confiança generalizada.

O índice de survey proposto por Yamagishi e Yamagishi (1994) também parece se sair relativamente bem na previsão do comportamento em situações experimentais. Em vez de basear as interpretações sobre confiança generalizada em uma única questão, com todas as fraquezas que advêm disso, o uso de um índice parece mais indicado. O índice é menos sensível aos efeitos de contexto e formulação e, portanto, apresenta menos viés (Smith, 1997). Pode parecer um tanto irônico que a disciplina que inventou as escalas de confiança generalizada continuou a desenvolvê-las e a aumentar o número de itens presente em seus índices, ao passo que isso não aconteceu com a mesma intensidade na ciência política.

A mensuração comportamental da confiança com modelos experimentais, usando jogos do ditador benevolente ou outros modelos (cf. Bohnet et al., 2001), parece mais robusta, mas com objetivos diferentes do que aqueles usualmente impostos por surveys. Uma combinação de surveys e métodos experimentais aumentaria a acuidade da interpretação dos resultados e provavelmente melhoraria a validade das conclusões. $E$ até que seja aplicado nos surveys um modelo de mensuração da confiança generalizada isento suficientemente de vieses, haverá sempre o risco de uma sombra de dúvida sobre a validade dos resultados obtidos com uma única questão. 


\section{BIBLIOGRAFIA}

BACHARACH, M \& GAMBETTA, D. (2000) Trust in Signs. In: COOK, Karen (ed.) Social Structure and Trust. Nova York, Russell Sage Foundation.

BANAJI, M. R. \& HARDIN, C. D. (1996) Automatic stereotyping. Psychological Science, 7: 136 - 141.

BELSON, W R. (1981). The Design and Understanding of Survey Questions. Ashgate, Adlershot.

BOHNET, I., FREY, B. \& HUCK, S. More Order with Less Law: On Contract Enforcement, Trust, and Crowding. American Political Science Review, 131(95).

COLEMAN, J. (1990) Foundations of Social Theory. Cambridge, Harvard University Press.

COUCH, L. \& JONES, W. (1997) Measuring Levels of Trust. Journal of Research in Personality. 31: 317-336.

DEUTSCH, M. (1958) Trust and Suspicion. Journal of Conflict Resolution, 2(4): 265-279.

FISMAN, R. \& KHANNA, T. (1999) Is Trust a Historical Residue? Information Flows and Trust Levels. Journal of Economic Behavior and Organization, 38(1):79-92 (janeiro).

FUDENBERG, D. \& TIROLE, J. (1991) Game Theory. Cambridge, MIT Press.

FUKUYAMA, F. (1995) Trust: The Social Virtue and Creation of Prosperity. Nova York, Free Press.

GAMBETTA, D. (1996) The Sicilian Mafia: The Business of Private Protection. Londres, Harvard University Press.

GAUTSCHI, T. (2000) History Effects in Social Dilemma Situations. Rationality \& Society, 12(2):131163.

GLAESER, E., LAIBSON, D., SCHEINKMAN, J. \& SOUTTER, C. (1999) What is Social Capital? The Determinants of Trust and Trustworthiness. NBER Working Paper $\mathrm{n}^{\circ}$. W7216.

Journal of Economics, 65: 811-846 (agosto). (2000) Measuring Trust. Quarterly

GRANOVETTER, M. (1973) The Strength of Weak Ties. American Journal of Sociology. 78:13601380.

HARDIN, R. (1997) Distrust. Russell Sage Foundation conference on Distrust, Bellagio, Itália, 13-17 outubro, disponível na intemet, http://www.russellsage.org/publications/working papers trust.htm [6 de agosto de, 2001].

(1999) Do we want trust in govemment? In: WARREN, M. (ed.) Democracy \& Trust. Cambridge, Cambridge University Press.

HAYASHI, N., OSTROM, E., WALKER, J. \& YAMAGISHI, T. (1999) Reciprocity, Trust and the Sense of Control: A Cross-Societal Study. Rationality \& Society, 11(1):27-47.

HOOGHE, M. (2000) Value Congruence within Voluntary Associations. A Social Psychological Extension of Social Capital Theory. Trabalho preparado para apresentar na Reunião Anual de 2000 da American Political Science Association, Washington, D. C., 31 de agosto-3 de setembro.

HWANG P. \& BURGERS, W. (1997) Properties of Trust: an analytical view. Organizational behavior and human decision processes, 69 (1):67-73.

INGLEHART, R. (1997) Modernization and Postmodernization: Cultural, Economic and Political Change in 43 Societies. Princeton, Princeton University Press. 
1999) Trust, well-being and democracy. In: WARREN, M. (ed.) Democracy \& Trust. Cambridge, Cambridge University Press.

JONES, G. (1998) The experience and evolution of trust: implications for cooperation and teamwork. Academy of Management Review, julho.

KRAMER, R. (1999) Trust and distrust in organizations: Emerging perspectives, enduring questions. Annual Review of Psychology.

KROSNICK, J. (1999) Survey Research. Annual Review of Psychology.

LAPIERRE, R. (1934) Attitudes and Actions. Social Forces, 13: 333-338.

LA PORTA, R., LOPEZ-DE-SILANES, F., SHLEIFER, A. \& VISHNY, R. (1997) Trust in Large Organizations. American Economic Review, 87: 333- 38 (maio).

LEVI, M. (1998) A State of Trust. In: LEVI, M. \& BRAITHWAITE, V. (eds.) Trust and Governance. Nova York, Russell Sage Foundation.

LIN, N. (2000) Social Capital: Social Networks, Civic Engagement, or Trust? Trabalho apresentado no workshop sobre Capital Social, Departamento de Sociologia, Universidade de Trento, 19-20 de outubro, Trento, Itália.

LUHMAN, N. (1979) Trust and Power. Nova York, Wiley.

MILLER, A. \& MITAMURA, T. A sair. Are Surveys on Trust Trustworthy? Nova York, Russell Sage Foundation.

OSTROM, E. (1998) A Behavioral Approach to the Rational Choice Theory of Collective Action. American Political Science Review, 92 (março).

PAXTON, P. (1999) Is Social Capital Declining in the United States? A Multiple Indicator Assessment. American Journal of Sociology, 105: 88-127.

PUTNAM, R. (1993) Making Democracy Work - Civic Traditions in Modern Italy. Princeton, Princeton University Press. Simon \& Schuster.

(2000) Bowling Alone: The Collapse and Revival of American Community. Nova York,

ROBINSON, R. \& JACKSON, E. (2001) Is Trust in Others Declining in America?: An Age-PeriodCohort Analysis. Social Science Research, 30: 117-145.

ROSENBERG, M. (1956) Misanthropy and political ideology. American Sociological Review, 21: 69095.

ROTHSTEIN, B. (2000a) Social Capital and Institutional Legitimacy. Trabalho preparado para apresentar na Reunião Anual de 2000 da American Political Science Association, Washington, D.C., 31 de agosto-3 de setembro.

(2000b) Trust, Social Dilemmas and Collective Memories, Trabalho preparado para apresentar na Reunião Anual de 2000 da American Political Science Association, Washington, D.C., 31 de agosto-3 de setembro

SABETTI, F. (2000) The Search for Good Goverment: Understanding the Paradox of Italian Democracy. Montreal e Kingston, McGill-Queen's University Press.

SANDERS, D. (1995) Behavioural Analysis. In: MARSH, D. \& STOKER, G. Theory and Methods in Political Science. Londres, Macmillan Press Ltd.

SMITH, T. (1997) Factors Relating to Misanthropy in Contemporary American Society. Social Science Research, 26:170-196. 
STOLLE, D. 1998. Bowling together, bowling alone: the development of generalized trust in voluntary associations. Political Psychology, 19:497-525.

USLANER, E. (1999) Democracy and Social Capital. In: WARREN, M. (ed.) Democracy \& Trust. Cambridge, Cambridge University Press.

YAMAGISHI, T. \& YAMAGISHI, M. (1994) Trust and commitment in the United States and Japan. Motivation and Emotion, 18(2): 129-166.

YAMAGISHI, T., KIKUSHI, M. \& KOSUGI, M. (1999) Trust, Gullibility and Social Intelligence. Asian Journal of Social Psychology, 2(1): 145-161.

YAMAGISHI, T. (1998) Trust and Social Intelligence: The Evolutionary Game of Mind and Society. Tóquio, Tokyo University Press.

Recebido para publicação em fevereiro de 2002 Tradução e publicação autorizadas pela autora Tradução de Pedro Maia Soares 